\title{
The outcomes of inadequate assimilation of Roma in socialist Romania
}

\author{
Silvia Ursu \\ s_ursu@yahoo.com
}

The paper analyzes the effect of the 'assimilation' policies (housing, education, employment, pronatalist) promoted by Ceaussescu's socialist regime toward the Roma on the extreme degradation of their social and economic status in the transition period which followed. The failure of these policies increased their discrimination and deteriorated the community social ties, locking the Roma in a vicious inter-generational cycle of poverty and exclusion. To support this argument further, an intra-group comparison between a deprived Roma community, Brazilia, which was heavily influenced by the communist 'assimilation' policies and a better-off Roma community, Boghis,, which stayed isolated and preserved its ethnic identity was carried out.

\section{Introduction}

Transition to the market economy marked a period of rapid decline in the quality of life and impoverishment of the general population in the former socialist Romania. However, the most affected by the socio-economic changes brought by transition were the Roma.

Inspired by the North American literature on urban deprivation and exclusion, a number of social scientists preoccupied with the study of the Roma 'problem' in Central and Eastern Europe, categorized the Roma as the 'underclass' of post-socialism (Emigh et al., 2001; Ladányi, 2001; Magyari et al., 2001). They are characterized by persistent poverty, they have limited or no access to opportunity structures, low quality social capital and social networks, so that "those in the underclass have almost no chance of finding roles in the new division of labour or of having 'normal' jobs, income, housing, social security, or access to better education for their children" (Ladányi et al., 2000 in Stewart, 2001a, p.2). As in the case of the American urban underclass formation, Emigh et al. (2001) identified discrimination, structural economic transformations (Wilson, 1987, pp.20-62) and segregation (Massey and Denton, 1993, pp.3-9) as the main factors leading to the formation of Roma 'underclass' in Eastern Europe. They argue that the deindustrialization following the collapse of the planned economy led to a decline in well paid low-skill work which was usually performed by the lower segments of the socialist working class, and left most of the Roma unemployed and unemployable.

There is much resemblance, indeed, between the experiences of deprivation of African-Americans in the inner-cities and the Roma in Central and Eastern 
European countries; therefore, it is difficult to contest the authors' borrowing of North American theoretical concepts referring to urban poverty in describing the evolution of socio-economic situation of the Roma. However, transition was a much more complex process than the economic transformations in the U.S. in the 1970s, affecting not only members of the minority groups, but also a large segment of the majority. Nevertheless, the Roma suffered most from these changes. After 10 years of transition an improvement in the socio-economic situation of all ethnic groups in Romania, but the Roma, is noticed. The improvement in the case of Roma is minimal or even lacking. In this context, I hypothesize that the inefficient assimilation policies promoted by most Communist regime in Romania between 1950s and 1980s, determined the marginalization of Roma by leaving them without skills, means and opportunities to fight the hardships brought by the transition to a market system. The failure of these assimilation policies increased their discrimination and deteriorated the community social ties, locking the Roma in a vicious intergenerational cycle of poverty and exclusion.

The assimilation policies promoted by the Romanian Communist Party (RCP) accelerated the shift from their identification as a distinct ethnic group with distinct traditions and lifestyle, which were discriminated against but generally accepted by the non-Roma, to their categorization as a socially inferior group, a categorization which is more salient in terms of social stigma and discrimination than the previous. In the absence of these policies, the group would most likely still have experienced increasing poverty and degradation of quality of life, for these were the experiences of the general population in post-Socialist Romania, however, they would have been better prepared to cope with the challenges of transition, thus, avoid being marginalized and deprived of life chances to the extent of an 'underclass'.

The aim of this short paper is to elucidate the content of the Roma assimilation policies promoted by the RCP during the Socialist period and their negative outcomes for the transition. In order to make my argument stronger, I will undertake a case study: an intra-group comparison between a deprived Roma community which was heavily influenced by the communist 'assimilation' policies and a better-off Roma community which stayed isolated and preserved its ethnic identity.

\section{The effects of the Communist policies on Roma marginalization and deprivation}

The main policies promoted by RCP that aimed at assimilating Roma in the Romanian society during Socialism were: compulsory education, sedentarization and housing 'systematization', 'integration to work', and Ceausescu's active pronatalist policy.

The dual relationship between the Roma and the majority of the population [on one hand being needed for their skills and craftsmanship, on the other, being stigmatized] found a reflection in the Romanian Communist Party's (RCP) approach toward the Roma. Until 1970s the party's approach was characterized 
by lack of policies altogether, which permitted prejudice and the emergence of "Gypsies" as a problematic social group, followed by active Gypsy "problem" solving policies in reply to the previous lack of approach (Beck, 1984). The failure of these policies lied in the fact that they aimed at reaching short-term quantitative results such as high school enrolment ratio or high socialist labour participation without treating the roots of the social problems that Roma were confronted with.

The character of socialist Roma policies depended on the RCP's vision of minority culture in general, and the Roma in particular, and of economic progress. The RCP was exploiting the arguments of the Marxist-Leninist theory of ethnicity, which operated in terms of class and not of ethnic minority belonging, for its nationalistic purposes. The Romanian culture was seen superior to the culture of any other minority group and the party was aiming for a gradual elimination of national differences through the assimilation of ethnic groups. Nevertheless, because of better mobilization and active intelligentsia enrolled in the Romanian Communist Party, the Hungarian, German, and Serbian minorities obtained their cultural rights and education in their native language. The officials felt that the Gypsies, unlike other minorities, had neither a "protective state", nor a "history", nor a "culture and civilization" through written languages to justify their claims for minority rights (Crowe, 1991, p.69). Thus, they were never considered a national minority during the Communist rule. Giving up their ethnic identity and lifestyle was the price of admission in the 'normal' Romanian society.

Secondly, modernization and advanced forms of production became central to Romanian values during socialism and the 'backward' and 'uneducated' Roma had to embrace those values before given any minority rights. Michael Stewart (Stewart, 2001b, p.83) incorporated the policy of the Hungarian Communist Party's policies toward Roma in the following formula:

$($ Gypsy $) *($ socialist wage-labour + housing + education $)=($ Hungarian worker $) *($ Gypsy folklore)

A similar situation is characteristic for Romania, except the folklore. Ceaușescu limited the number of Gypsies in folk ensembles to $60 \%$ of the fear that this could spoil the 'superior' Romanian culture (Pons, 1999, p.32). The cultural deprivation distorted the identity, coherence and sense of solidarity of the Roma minority.

There were two aspects to the housing policy for the Roma. The 1950s forced sedentarization which involved the confiscation of their horses and carriages (Pons, 1999). The second was Ceaușescu's "systematization" programme in 1980s which involved the destruction and removal of unhygienic Roma settlements and houses with an end-goal of dispersing the large groups of Roma among the Romanian population for an efficient integration. They received housing in apartment buildings in urban areas or were placed in nationalized houses, which were confiscated from German emigrants (Helsinki Watch, 1991). 
Although these policies aimed at improving housing conditions, they failed in major part due to their perverted implementation. After "systematization" the Roma were concentrated in flats in urban areas which formed urban ghettos. The quality of housing was low and their dwellings degraded rapidly. They were moved in small apartments, insufficiently spacious for the large Roma families. The Romanian sociologist Nicolae Gheorghe, who worked for the RCP Commission on Demography from 1976-1989 (Helsinki Watch, 1991, p.23), testified that he was shocked by the misery of those blocks: "So many people concentrated in such a small amount of space. The blocks of flats were built in bad condition. Water is not running. Some Romanians live in these conditions as well, but mostly Gypsies. The result is a deterioration of social life."

The Roma who were moved in confiscated houses from German emigrants faced strong resentment from the non-Roma neighbours and in many cases did not receive property papers for those houses being left at the risk of evacuation during the transition when nationalized property was returned to owners.

During transition, the results of the housing policies were residential segregation, overcrowding and bad housing conditions. Many of the Roma, who received apartments among the non-Roma, sold them in order to avoid the prejudice, spent the money, and moved back to huts and tents in their previous settlements. In some cases, the restitution of land to previous owners led to the spatial isolation of Roma houses from social institutions such as the school, the town hall, the bakery as it happened in the Romanian village Fisze (Pons 1999, p.76). Segregation left the Roma out of the electrification programme and connection to the water system. ICCV $(2002$, p.32) found that the Roma experienced worse housing conditions compared to the majority population and that the average number of people per room for Roma was almost twice that of the general population. In $25.6 \%$ of the Roma households the number of people per room was 3.01, compared to the corresponding percentage for the entire population $-1.7 \%$.

The housing policy was accompanied by the socialist employment policy which strived to achieve full-employment, even if that meant to artificially create unnecessary jobs for people. The Roma, who until then were 'idle' or were performing 'backward' jobs, needed to be integrated into the socialist working system. This was done by employing them in the lowest niches of the Romanian socialist economy mainly as collective farm workers and as unskilled manual workers. According to the 1956 and 1966 censuses there was an increase in the number of workers and collective farmers of $6.92 \%$ and $23.65 \%$ respectively (Gilberg, 1974, p.460). The collective farmers were the most poor of all the socialist workers (Pons, 1999). Moreover, the Gypsies continued to have a low mobilization in the functionaries/intellectuals category and even experienced a decline in 1966.

During the 1970s the "integration to work" policy intensified. However, it did not integrate but forced the Gypsies to work through the Decree 153/1970, which persecuted the unemployed and threw them in jail for six months 
(Helsinki Watch, 1991). Although there was an alternative Decree 25/1969 related to parasitism, which made the government take responsibility to find a job for the unemployed, the Decree 153 was predominantly used in relation to unemployed Roma. In an interview with Helsinki Watch (1991, p.28) Nicolae Gheorghe stated that Decree 153 targeted principally the Roma.

The 1983 Report compiled by the Propaganda Section of the Central Committee informed that the RCP's attempts to integrate the Roma to work did not produce the expected results. In 1977 many of the Roma had temporary work and out of 65,000 only 900 were qualified. In 1977, 32.7\% of the Roma fit for work and $48 \%$ of Roma women were unemployed. In 1983, the situation worsened (Romanian Communist Party, 1983, p.109).

The goal of employment policies to integrate the Roma was a short-term one and led to the expulsion of this minority from the labour market during transition which perpetuated their poverty and marginalization. The restructuring of the large state enterprises after 1989 prompted the loss of jobs of unskilled worker, most of whom were Roma. In the context of discrimination outburst after the collapse, they were more likely than Romanians to lose their jobs. The Communist Party's support of full-employment motivated the creation of artificial unskilled jobs such as street-sweeping, which became unnecessary and unsustainable in transition.

Due to the fact that industrialization and nationalization decreased the demand for the products of the Roma traditional trades and forcefully transformed them into seasonal collective farmers, they lost their skills for these crafts. In the beginning of transition they were left out of the land privatization reform, and having lost their traditional skills, they were excluded from the labour market with no opportunities and means to enter it again. The dependency on the Communist production system and the disappearance of their competencies, which maintained the functionality of the relationship with the non-Roma, made them vulnerable when the system collapsed.

Furthermore, the Roma assimilation was to be realized by introducing compulsory education for them. Before socialism the level of education of the Roma was much more inferior compared to that of the non-Roma, due to their nomadic lifestyle and poverty. In 1956, the illiteracy rate among Roma over 8 years was high - $37.7 \%$, compared to the $10.9 \%$ of Romanians from the same age category (Gilberg, 1974, p.447). Out of the few Gypsies who were participating in education, the bulk was enrolled in primary school $(18.17 \%)$, while there were virtually none enrolled in secondary and higher education. At seven-year level, less than 500 could be found (Gilberg, 1974, p.455). According to the national census, by 1966 almost all Roma were enrolled in primary schools - 96.61\%, circa an $80 \%$ increase in one decade (Gilberg, 1974, p.463). However, their representation in vocational and technical schools and lyceums remained symbolic. In higher education Roma registered no gain at all. 
The 1983 Report on Integration of Gypsies (Romanian Communist Party, 1983) revealed that many adult Gypsies were semi-literate or illiterate. Not understanding the necessity of schooling they were not motivating their children to attend school. Thus, the Roma sedentarization did not increase the school enrolment because understanding the importance of education lacked. The Report also noted that one of the reasons for low school attendance among Roma was poverty - a proof that the Party did not achieve the improvement of the Gypsies' economic position.

Despite the accomplishments which were registered on primary level, the reality of education conditions for Roma during the regime was different. The Roma were not allowed to have schools with teaching in their own language and were enrolled in Romanian or Hungarian schools, where they faced discrimination from teachers and peers. Many of the Roma children did not speak another language but Romanes which was an obstacle to school integration and achieving good results. As a result, many of them were 'diagnosed' with learning disabilities and sent to the so-called 'special' schools for mentally disabled. This put obstacles for their later social integration (Mihok, 2003).

During the transition the situation did not change. In 1998 Roma school participation was $15-25 \%$ lower compared to the general population at primary level, $30 \%$ at gymnasium level, and almost $40 \%$ at the high school level (ICCV 2002, p.23). Moreover, the few Roma who did gain higher levels of education during Communism gave up their ethnic identity to avoid prejudice and have access to the opportunities for social mobility. This left the marginalized Roma without social networks and support for upward mobility.

Thus, the results of Communist education policies for Roma were superficial. During socialism the enrolment rate registered an increase but only at primary level. Due to lower returns to education for Roma, lack of education among the adult population and discrimination faced in schools, the truancy and drop-out rates among Roma children increased in transition.

Finally, the 1966 Ceaușescu's active pronatalist policies and the generous monthly state allowance for every new born encouraged high birth rates and the creation of large Roma families in the next two decades. As previously discussed the large family size is a direct determinant of high poverty level. The high fertility favoured high numbers of school dropouts among Roma women and created difficulties for them to enter the labour market (Pons, 1999). This increased the dependency of Roma women on the state which was unable to fulfil its previous socialist commitments during the transition.

Other results of Ceaușescu's pronatalist and childcare policies in the 1970s and the lack of social and educational programmes in the 1980s were that they encouraged the Roma to abandon their children or place them in state institutions such as orphanages or healthcare centres for disabled children (Pons, 1999). This condemned the new generation of Roma to marginalization 
once out of the institutions because these institutions usually failed to develop their skills for social integration.

The Communist assimilation policies increased the vulnerability of the Roma to socio-economic transformations in transition by destroying the family and community social networks. This shattered the opportunities for social mobility and made it difficult to exit deprivation. The following intra-group comparison of two Roma communities aims to illustrate the importance of social capital and networks for a Roma community's economic advancement in transition and how the Communist policies destroyed these networks in one of the communities condemning it to extreme poverty, marginalization and discrimination by the non-Roma.

\section{Case studies: The Roma of Brazilia and Boghiş}

The case studies are taken from an ethnographic research conducted by Gabriel Troc (2002) in two Roma communities in Transylvania: Brazilia in Nusfalau village and Boghiș. The first one experienced rapid impoverishment, extreme deprivation and discrimination during the transition, while an opposite situation is characteristic for the second community. Some of the Roma in Boghiş are even more affluent than the average rural inhabitant (Troc, 2002, p.50).

I selected the two case studies controlling for variables such as ethnic composition, residential segregation and poverty during the socialist regime. Both of these settlements are homogeneously populated by Roma, physically segregated from the non-Roma and were poor during the Communist rule.

The central differences between these two communities lie in their ethnic and social rapport with the non-Roma and the degree to which they were influenced by the Communist policies. I argue thus that it was these differences that made the Roma of Brazilia more vulnerable during the transition and augmented their poverty and social exclusion compared to the Roma of Boghiș.

Regarding the established relation with the non-Roma, the Roma of Brazilia occupied the lowest ethnic and social position since their first presence in Nusfalau village. Until 1850 s, they were serfs of the local aristocrat working as brick-makers or agricultural labourers. After their emancipation, they were employed on and off by Hungarian or Romanian peasants as cheap labour force. To avoid discrimination they tried to adopt the non-Roma 'ways', giving up their dressing style, some of the social norms and traditions. However, their mobility outside their ethnic group stayed limited.

Unlike the 'Brazilians', the Roma of Boghiș were brought to the village in 1950s by the Communists for two reasons by the author's assumptions: to change the ethnic balance of an increasingly all Hungarian village and to divide the larger group of the Roma from Huseni (Troc, 2002, p.66). Their 'wilder' look and lifestyle kept the non-Roma peasants at a distance and generated a 'certain' respect for their customs and occupations. 
The 'Brazilian' Roma were heavily influenced by the Communist assimilation and 'integration to work' policies, while the Roma of Boghiș were permitted to preserve their mobility, traditional lifestyles and occupations.

The Communist influence on the 'Brazilian' Roma can be divided into two periods, which, as in the case of the general Roma population, are characterized by a duality of approaches - ambivalence and forced 'integration to work'. During the ambivalence period, the Roma were moved to the district Brazilia, a residentially segregated housing area which was developed after WWI in the Eastern part of the village. Despite their 'hygienic' and 'civilizing' intentions, the Communists did not provide any conditions such as sewerage, wells, electrification in those houses.

In the 1950s, the brick factory was nationalized and modernized, thus, many Roma were left without jobs in the community. In this way they lead a seminomadic lifestyle between 1950-1980 searching for demand for their bricks and services. This lifestyle condemned them to low level of education and poor housing. According to the author's findings they were not trained in modern professions and many of them lacked identification papers (Troc, 2002, p.61).

During 1980-1989, the Romanian Communist regime became very restrictive and many Roma were forced to work on collective farms as temporary workers. The Communist policies from this period had two important negative effects on the Roma of Brazilia. By maintaining their status as temporary inhabitants (more than half of the year was spent on large socialist farms) they allowed for the local authorities' indifference toward their living conditions and level of education. Secondly, by engaging them mainly in temporary work, these policies made them ineligible for pensions and other social benefits.

Due to their strong traditional lifestyle the Communists considered the Roma of Boghiș too wild for a short-term assimilation policy, thus, they were allowed to maintain their occupations and habits in a legal form. They received a state license which permitted them to collect scrap metals and glass and sell them to special state recycle centres. These licenses also allowed them to keep their highly mobile lifestyle. Although, during socialism, they were much poorer and marginalized than the rest of the population and there were no state programmes to address their problems, they were never forced to employment in agriculture and industry. They travelled around the regional fairs and markets with their horse carts engaging in various commercial and exchange activities. At the same time, unlike the 'Brazilians' they stayed less off-house and they did not have a "second residence" on socialist farms (Troc, 2002, p. 66). This made them more concerned with their homes and housing conditions. The most important characteristic of the Boghiș Roma, which favoured their economic advancement in transition, was the fact that the community remained integrated and preserved its social ties and networks.

The outcome of Communist policies for the 'Brazilians' was dramatic during the transition. Although they worked on collective farms, the 'Brazilian' Roma were 
left out of the land privatization reform. They did not receive the property rights even to the land that their houses were built on. Moreover, in the first three years after the regime collapsed most of them found themselves unemployed. The Roma who worked in the extractive industry were first dismissed. The ones who worked for the collective farms and the brick factory lost their jobs after the privatization. Beginning with 1993, the economic situation of the 'Brazilians' worsened progressively (Troc, 2002, p.67).

In the case of the Boghiş Roma, their independence and high mobility, knowledge of the market, as well as their strong social ties, allowed the entire Roma community to take advantage of the new opportunities of the informal economy during the transition. The first opportunity was the "walnuts affair", which involved exchanging industrial-made vessels, which were provided by a Roma employer to the Boghiș Roma, for walnuts from the non-Roma peasants. The employed Roma cracked the walnuts and gave the kernels to the employer, who sold them in Arad to an entrepreneur, who processed them for export in Germany and Austria. The second opportunity was commerce - horse dealing and vegetables commerce with the non-Roma peasants (Troc 2002, p.71). The commercial relations with the peasants created a kind of 'business-partner equality' between the Roma and the non-Roma.

Thus, the Communist policies coupled with an inferior ethnic and social status destroyed the social networks and the traditional skills possessed by the Roma of Brazilia making it difficult for them to stay and enter the market during the transition and exit poverty, as the Boghiş Roma succeeded. Furthermore, the author found ethnographic evidence that the inferior economic position of the 'Brazilians' perpetuated their social marginalization and discrimination by the non-Roma, while the higher economic position of the Boghiș Roma fuelled a functional relationship of exchange with the non-Roma and ensured a certain degree of equality, for example, in education and housing conditions (Troc, 2002).

\section{Conclusion}

The aim of this paper was to show how the inadequate assimilation policies promoted by RCP made the Roma more vulnerable to the economic transformations during the transition compared to the general Romanian population that they became the post-socialist 'underclass', characterized by extreme deprivation and social exclusion. The intra-group comparison between a Roma community which was heavily influenced by the Communist policies and another Roma community which was less victimized by the regime further supported my argument that the failure of these assimilation policies increased their discrimination and deteriorated the community social ties, locking the Roma in a vicious inter-generational cycle of poverty and exclusion. Most of the poor Roma underwent similar conditions as the Roma of Brazilia, thus, it is possible to infer that the Communist policies negatively influenced the majority of the Roma which constitute 'underclass' of transition. 
Thus, in order for the Roma to be able to exit their inferior socio-economic position, they need social capital. This can be achieved mainly through increased access to quality education, which will develop their social capital. Social capital will, subsequently, provide valuable networks to access jobs and higher educational opportunities. Nevertheless, the Romanian government must seek to achieve this goal not through targeted programmes, but through programmes which pursue the accomplishment of equality of life chances. The targeted programmes provide opportunities to individuals who are already better off and fail to assist the entire socially excluded group (Wilson, 1987). Moreover, the targeted programmes by benefiting only certain groups do not generate and sustain public support (Wilson, 1987). Moreover, in the case of Romania, where the transition negatively affected not only the socio-economic situation of the Roma, but also that of many non-Roma, these programmes will intensify the existing prejudice and ethnic conflict.

Wilson (1987) proposed for the American society the introduction of universal programmes that would benefit all the segments of the population. In this way the groups that have experienced the most severe economic dislocations, including the ghetto underclass, would be helped most. However, the size of the U.S. economy and the type of its welfare state are very different than those of Romania. At the moment, in conditions of continuing economic stabilization and development, it might be financially difficult, if not impossible, for the Romanian government to introduce universal economic and social assistance programmes.

Therefore, the government's principal solution to the Roma 'problem' is investing in their education by providing them with opportunities to study in their own language or integrating them efficiently in Romanian or Hungarian schools with support for learning Romanian or Hungarian languages. The first solution - separate schools or classes with teaching in Romanes - may fail since it already has precedent which did not yield the expected results (see Pons, 1999), as well as, in conditions of discrimination and exclusion it may perpetuate the existing situation. At the same time, due to the fact that many Roma are partially assimilated and do not speak Romanes as their native language, but Romanian or Hungarian, separate schools or classes in Romanes may create a divide inside the Roma group itself, making more difficult the integration of the Roma students, who attended these schools or classes, in higher education or labour market that operate in Romanian or Hungarian.

The second option of creating special preparatory classes to assist the Roma students in learning Hungarian or Romanian, and then integrating them in nonRoma schools and classrooms, seems to be a better solution to the problem. Achieving equality in education status starting with primary level will provide the Roma students with means to compete for scholarships in secondary and higher education. The contact in joint classrooms may reduce the level of prejudice and would prevent the resentment from the non-Roma students that is generated in the case of targeted affirmative action programmes. 


\section{References}

Beck, S. (1984) 'Ethnicity, Class and Public Policy: Tiganii/Gypsies in Socialist Romania' in Shangriladze, K. K. and Townsend, E.W. (eds.) Papers for the V. Congress of Southeast European Studies, Belgrade: Slavica Publishers, pp. 19-37.

Crowe, D. (1991) 'The Gypsy Historical Experience in Romania' in Kolsti, J. and Crowe,

D. (eds.) The Gypsies of Eastern Europe, New York: M.E.Sharpe, Inc., pp. 61-80.

Emigh, R. J. and Szelenyi, I. (2001) Poverty, Ethnicity, and Gender in Eastern Europe during the Market Transition, Westport: Praeger Publishers.

Emigh, R. J., Fodor, E. and Szelenyi, I. (2001) 'The Racialization and Feminization of Poverty?' in Emigh R. J. and Szelenyi, I. (eds.) Poverty, Ethnicity, and Gender in Eastern Europe during the Market Transition, Westport: Praeger Publishers, pp.1-32.

Gilberg, T. (1974) 'Ethnic minorities in Romania under Socialism', Eastern European Quarterly, 7:4, pp. 435-463.

Helsinki Watch (1991) The Persecution of Gypsies in Romania. Destroying Ethnic Identity, New York: Human Rights Watch.

Institutul pentru Cercetarea Calitatii Vietii (2002) Romii in Romania, Bucaresti Editura Expert.

Ladanyi, J. (2001) "The Hungarian Neoliberal State, Ethnic Classification, and the Creation of a Roma Underclass", in Emigh, R.J. and Szelenyi, I. (eds.) Poverty, Ethnicity, and Gender in Eastern Europe during the Market Transition, Westport: Praeger Publishers, pp. 67-82.

Magyari, N., Magyari-Vincze, E., Popescu, L. and Rotariu, T. (2001) 'The Social Construction of Romanian Poverty: The Impact of Ethnic and Gender Distinctions' in Emigh, R. J. and Szelenyi, I. (eds.) Poverty, Ethnicity, and Gender in Eastern Europe during the Market Transition, Westport: Praeger Publishers, pp. 123-156.

Massey, D. and Denton, N. (1993) American Apartheid: segregation and the making of the underclass, Cambridge, Mass; London: Harvard University Press.

Mihok, B. (2003) 'Raport de țară Romania' in Graf, I. (ed.) Rromii in Europa de Sud Est - Raporturi de țara despre condițiile cadru, sociale și juridice, București: Friedrich Ebert Stiftung,

Pons, E. (1999) Țiganii din România - o minoritate în tranziție, București: Compania "altFEL".

Romanian Communist Party (1983) 'Report on Integration of Gypsies of the Propaganda Section of the Central Committee of the Romanian Communist Party' in Helsinki Watch (ed.) The 1991 Helsinki Watch Report on the Persecution of Gypsies in Romania, New York: Human Rights Watch, pp. 108-116.

Stewart, M. (2001a) 'Deprivation, the Roma and the "underclass"' in Chris Hann (ed.) Postsocialism: Ideas, Ideologies and Practices in Europe and Asia, Routledge. 
Stewart, M. (2001b) 'Communist Roma policy 1945-1989 as seen through the Hungarian case' in Guy, W. (ed) Between Past and Future: the Roma of Central and Eastern Europe, Hatfield: University of Hertfordshire Press, pp. 71-92.

Troc, G. (2002) 'A state of despair: Roma (Gypsy) population during transition Transylvianian case studies' Studia Universitatis Babes-Bolyai, Studia Europaea, XLVII, 1-2, pp. 49-89.

Wilson, W.J. (1987) The truly disadvantaged: the inner city, the underclass, and public policy, Chicago: University of Chicago Press. 